\title{
The "PantryApp": Design Experiences from a User-Focused Innovation Project about Mobile Services for Senior Citizens
}

\author{
Anna Sigridur Islind \\ University West, Sweden \\ anna-sigridur.islind@hv.se
}

\begin{abstract}
This experience report aims to reflect on a design initiative conducted as a user-focused innovation. It is based on a research and development project about mobile commerce. Herein, I include various forms of mobile services that accumulate the core function of mobile payments. The target group of the design was senior citizens who need to have their grocery shopping done in a more safe and convenient way. In this report I will particularly focus on the design process and the design product.
\end{abstract}

Keywords: Design Experiences, Senior Citizens, Mobile Application and Services, Mobile Payments.

\section{Introduction}

This experience report aims to reflect on a design initiative conducted as a userfocused innovation. It is based on an action design research project about mobile services and mobile payments [1]. The target group of the design is senior citizens and other caretakers that need their grocery shopping done in a more safe, sufficient and convenient way. The focus in this report lies on the design process and the design product.

\subsection{The Problem}

People need food and grocery shopping is a part of everyday life. For people with disabilities, diseases, impaired vision, high age or other problems that render them unable to take care of themselves completely, going grocery shopping is out of the picture. These citizens belong to the home care system and receive help from caregivers that tend to their needs and see to that they get fresh groceries. The actual situation in the case of the studied municipality, the caregivers collect handwritten shopping lists and money and then shop for five caretakers at a time. This quite often results in mistakes and the caregivers have a tendency to bring home the wrong groceries. Problems have also occurred during the payment process. To hand money or a payment card over to a caregiver, which a caretaker might be meeting for the first time, is precarious since time to establish important trust is not always available. Furthermore, 
the caregivers do not consider it optimal to handle money and having the forced responsibility of bringing the right change back to the five caretakers.

Some caretakers have portrayed mistrust towards the caregivers and have occasionally made allegations against the caregivers, accusing them of stealing. These kinds of incidents usually have a logical explanation and are resolved in a good manner but put unnecessary stress on all parties involved. Additionally, the caregivers have educated themselves in care or nursing and should not be forced to go grocery shopping.

Consequently, this is a process with a lot of human factors that can easily go wrong. Nevertheless, after almost one and a half year of working with this project and this problematic process, it is obvious that as long as the money factor is involved in this process, there will be mistrust.

\section{The Design of the PantryApp}

The design of the PantryApp was reflected by the steps: investigation, exploration, composition and evaluation [2].

\subsection{Investigation}

The investigation has included extensive empirical research, in terms of interviews in focus groups in addition to individual interviews. As this is a project with user focus, the key-persons in the interview phase were the senior citizens (caretakers), a group of retired citizens that do not yet belong to the Swedish home care system as well as the caregivers. The caregivers have tacit knowledge so they were able to, through interviews, distinguish how they perceived their daily work tasks into the tiniest detail. The owners and employees in the store that delivers the groceries have also been interviewed regularly. The caretakers have shed light on their specific needs and wants. Their lack of technology knowledge implied that they all in fact belonged to digital divide as presented by Selwyn, et al. (2003). These user groups have had the biggest influence, both in the interface design and in the usability design.

Leaders from all levels in the municipality in addition to politicians have been involved as well through giving feedback on the applications impact on the organizational structure. They helped crystalize how the organization works on a higher level.

\subsection{Exploration}

From being a software developer for six years to becoming a more user-focused designer has been a learning journey for me. My role as a project leader in this complex project has been the greatest experience yet. I have developed real passion for helping the caretakers and caregivers as I felt compelled to use my education for some greater good: to help those in need, and these wonderful senior citizens are certainly in dire need. This helped develop a sense of possibilities and led to the realization of what can be, rather than putting emphasis on what is (Nelson and Stolterman, 2012). At a certain point there was a shift in focus to how things could be 
done in the perfect world, full of possibilities. The first draft of this "perfect world" did not correspond to what the application later evolved into, since aiming for the perfect scenario is neither relevant nor realistic. This was merely a learning process for all parties and led to an even closer collaboration.

This close cooperation with the end-users resulted in a functional co-produced prototype, which has been redesigned for the next phase, a full-scale artifact. It answers the needs of today, but it requires nurture as well as careful and continuous cooperation to answer the needs of the future users. What we have today might not look or feel anything like what the future will hold but is certainly a start of something. This start of something has already, according to the caregivers themselves, shown improvement possibilities in their daily work. Consequently, their role should evolve into a more meaningful care taking and nurturing one and resulting in them having more pride in their profession.

With the implementation of the PantryApp, both in its prototype stage and in the full-scale version, the handwritten shopping lists from the seniors are history. They now pick their products out in the PantryApp, which presents all products with pictures and sit in the comfort of their home alongside their caregiver that help them choose and order selected products.

The implementation has generated further needs and wants such as a guidance role for the caregivers that have been asked to provide nutrition advice. The caretakers have progressed as well. They have expressed curiosity towards what others buy, so a function that presents the most popular choices amongst all buyers has been implemented. The prototype version was only an android application but the full-scale PantryApp is platform independent at the request of both user groups. Taking this user-focused perspective has generated these new innovative user ideas continuously and thus made the application richer.

\subsection{Composition}

The application was designed and programmed in harmony with the organizational changes. This organizational development included designing a new schedule for the caregivers to go between the caretakers' homes in a more efficient manner to grocery shop via the PantryApp. The grocery store involved picks and packs the groceries and sent out an invoice directly to the senior citizens during the pilot phase. In the full-scale PantryApp, the caretakers pay directly within the application using mobile payments. The groceries are then picked up and delivered to the seniors' homes, by another party.

\subsection{Evaluation}

The users have expressed satisfaction towards the project as a whole and shown fulfillment regarding the new design of the full-scale application. Their gratitude gets me excited and enthusiastic to get to the next stage in the project. The anticipation is that a large group of caretakers alongside caregivers will find the artifact facilitating and useful and that the application will be implemented in numerous municipalities.

The money factor, already eliminated in the prototype phase, has influenced trustcreation between the caretaker and the caregivers to a great deal. The implementation of mobile payments in the full-scale application is expected to result in an even greater impact on the trust factor. 
The application allows the caretakers to gain control over their own economy and spending decisions again, that most of them lost years ago. The PantryApp even allows the caretakers to make the final decision about their grocery selection. Being in need of care, should not mean loss of control.

\section{Conclusions and Lessons Learned}

L1. End User Involvement: The concrete and direct involvement of senior citizens in the design process was essential. During that process it became clear that the senior citizens especially had difficulties seeing how things are possible without having an artifact right in front of their eyes. This may be due to the digital divide.

L2. Mediating Artifact: Before, there was a lack of caring communication between the caretakers and the caregivers. At present, the application is considered as a conversation starter as the caretakers now sit closer to their caregivers and they seem more relaxed with each other than they did before. There is no pressure to know each other beforehand or get to know each other on a personal level. The artifact actually links these two groups together in a community-of-practice kind of way.

L3. Professional Values: Daily problems in the professionals' practices regarding trust factor and handling money are accommodated through the artifact. The focus is now shifting from the role of a personal assistant towards the professional role of nursing and caring.

\section{References}

1. Sein, M.K., et al.: Action Design Research. MIS Quarterly 35(1) (2011)

2. Nelson, H., Stolterman, E.: The design way: Intentional change in an unpredictable world, 2nd edn. MIT Press, Cambridge (2012)

3. Selwyn, N., Gorard, S., Furlong, J., Madden, L.: Older adults' use of information and communications technology in everyday life. Ageing and Society 23, 561-582 (2003) 